\title{
Discoidin domain receptor 1 regulates bronchial epithelial repair and matrix metalloproteinase production
}

\author{
M.E. Roberts, L. Magowan, I.P. Hall and S.R. Johnson
}

\begin{abstract}
Discoidin domain receptor (DDR)1 is an extracellular matrix (ECM)-sensing receptor tyrosine kinase, which is activated by collagen and expressed in bronchial epithelium. DDR1 is responsible for maintaining the normal structure of skin and kidney epithelia and we hypothesised that DDR1 plays a regulatory role in bronchial epithelial integrity by transducing signals from the airway ECM.
\end{abstract}

Effects of DDR1 depletion were studied using RNA interference in primary human bronchial epithelial cells (HBECs) and BEAS-2B cells. The effects of overexpression of DDR1a and DDR1b in BEAS-2B cells were studied using a plasmid vector. We measured the effects on epithelial repair using a scratch wounding model, and levels of matrix metalloproteinases (MMPs) by gelatin zymography (MMP-2 and -9) and ELISA (MMP-7).

We showed that knockdown of DDR1 slowed epithelial repair by $50 \%$, which was associated with a reduction in levels of MMP-7, whilst DDR1 overexpression enhanced epithelial repair. DDR1 knockdown reduced proliferation of HBECs, but had no significant effect on adhesion to collagen I or other matrix substrates.

These data suggest that ECM signalling via DDR1 regulates aspects of bronchial epithelial repair, integrity and MMP expression in the airways.

\section{KEYWORDS: Bronchial epithelial repair, discoidin domain receptor, matrix metalloproteinase}

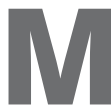

aintenance of epithelial integrity is essential for normal function of the bronchial epithelium, including host defence and epithelial barrier function. Bronchial epithelial injury and repair are features of respiratory diseases, such as asthma and the response to viral infection. Direct toxic insults, trauma or inflammatory processes cause the loss of epithelial cells, leading to exposure of basal epithelial cells and basement membrane, which then institute a repair process $[1,2]$. Epithelial repair is a complex process comprising proliferation, migration and adhesion. Initially, the remaining epithelial cells secrete a provisional matrix, predominantly composed of collagens I and III, and fibronectin. By adhering to this provisional matrix, these cells migrate to the site of injury. Later, cells distant from the wound edge undergo a proliferative response $[2,3]$. The process of restitution is also associated with and dependent on the production of secreted factors, such as epidermal growth factor (EGF) and trefoil factors, which promote bronchial epithelial repair by increasing the motility of epithelial cells [3-5]. Matrix metalloproteinases (MMPs) remodel the extracellular matrix (ECM), affect cell-ECM interactions and are known to be essential components of epithelial repair. MMP-7 is expressed constitutively by bronchial epithelial cells and in an MMP-7 knockout mouse model, bronchial epithelial repair is completely abolished following mechanical wounding [6]. Substrates of MMP-7 include the ECM component fibronectin, the cell-cell interaction molecule E-cadherin and proteases, including pro-MMP-2, which is also upregulated during the epithelial repair process [7].

The integrin family of ECM receptors and CD44, a cell surface glycoprotein, interact with ECM components and promote adhesion and migration of epithelial cells [8-16]. Discoidin domain receptors (DDRs) are a family of receptor tyrosine kinases whose cognate ligands are the collagen family, particularly collagens I-V: collagens I and III are significant components of the ECM produced during epithelial repair [17-19]. DDR1 is expressed in the bronchial epithelium and has been shown to be important in the maintenance of the normal structure of epithelia in the skin and kidney [20-22]. DDR1 is also required for arterial wound repair after injury [23]. In whole-lung

\section{AFFILIATIONS}

Division of Therapeutics and Molecular Medicine and Respiratory Biomedical Research Unit, University of Nottingham, Nottingham, UK.

\section{CORRESPONDENCE}

S.R. Johnson

Division of Therapeutics and

Molecular Medicine

University of Nottingham

D Floor South Block

Queen's Medical Centre

Nottingham

NG7 2UH

UK

E-mail: simon.johnson@

nottingham.ac.uk

Received:

March 122010

Accepted after revision:

Sept 152010

First published online:

Sept 302010 
samples from patients with idiopathic pulmonary fibrosis, a disease characterised by persisting epithelial injury [24], DDR1 mRNA together with MMP-7, MMP-2 and MMP-9 were strongly overexpressed when compared with normal tissue [25]. Taken together, these data suggest that DDR1 may play a role in this disease, perhaps by modulating epithelial repair and MMP activity.

We hypothesised that DDR1 plays a role in airway epithelial repair by transduction of signals between the ECM and epithelial cells to regulate epithelial repair and effectors of repair, such as MMPs. In this study, we undertook experiments to confirm the presence of DDR1 in bronchial epithelium and to investigate the influence of DDR1 on epithelial wound healing, proliferation, adhesion and levels of MMP-7, MMP-2 and MMP-9. We also investigated DDR1 expression in epithelium from patients with asthma (a disease characterised by abnormal epithelial integrity and repair) and nonasthma controls to examine if DDR1 is differentially expressed in asthma.

\section{METHODS}

\section{Cell culture}

BEAS-2B Cells (American Type Culture Collection, Manassas, VA, USA) were cultured in Dulbecco's modified Eagle's medium (DMEM)/F12 (Invitrogen, Paisley, UK) supplemented with $10 \%$ fetal bovine serum (FBS; PAA Laboratories, Yeovil, $\mathrm{UK})$ at $37^{\circ} \mathrm{C}$ in $5 \% \mathrm{CO}_{2}$. Subculture was undertaken using trypsin-EDTA (Sigma, Poole, UK). Human bronchial epithelial cells (HBECs) were obtained from Lonza (Wokingham, UK) or from biopsies obtained at bronchoscopy. Endobronchial biopsies were immediately transferred to the cell culture laboratory in warm PBS (Invitrogen). Biopsies were then dissected to isolate epithelial tissue under a low-power dissection microscope. Explants were transferred to six-well plates with a minimum volume of bronchial epithelial growth medium (bronchial epithelial basal medium (BEBM) supplemented with bronchial epithelial growth medium SingleQuot kit; Lonza) and incubated at $37^{\circ} \mathrm{C}$ in $5 \% \mathrm{CO}_{2}$ overnight to facilitate adhesion. The volume of medium was then increased and explants were grown in submerged cultures until cell numbers had expanded sufficiently to transfer to flasks. HBECs and cells derived from explants were harvested using trypsin-EDTA. Trypsin was neutralised using soybean trypsin inhibitor (Invitrogen) in PBS.

\section{DDR1 knockdown}

Cultured BEAS-2B cells were washed in bronchial epithelial "wounding" medium (BEWM) [3], consisting of BEBM containing retinoic acid, triiodothyronine, bovine pituitary extract and recombinant human insulin. They were then exposed to RNA interference (RNAi) transfection complexes composed of $2 \mu \mathrm{L} \cdot \mathrm{mL}^{-1}$ Lipofectamine ${ }^{\mathrm{TM}} 2000$ (Invitrogen) pre-incubated with $20 \mathrm{nM}$ small interfering RNA (siRNA) to DDR1 or Control Number 1 (DDR1 sense sequence: GCC AGU GAC ACU AAA ACA Att; DDR1 antisense sequence: UUG UUU UAG UGU CAC UGG Ctt; Applied Biosystems, Warrington, UK). For HBECs, cells were exposed to RNAi for $4 \mathrm{~h}$ and then recovered in BEWM for $48 \mathrm{~h}$.

\section{DDR1 overexpression}

BEAS-2B cells were transfected with the pIRES2-EGFP vector (Clontech, Saint-Germain-en-Laye, France), either with no insert used as the control, or the vector with active DDR1a, active DDR1b or a kinase-dead (kd) DDR1a variant that has previously been shown to prevent autophosphorylation at all tyrosine residues of DDR1 in response to collagen I activation (K618A, a loss of function substitution in the kinase domain) [26]. All transfections were performed using Fugene (Roche, Burgess Hill, UK). DDR1 constructs were kindly supplied by the late W. Vogel, (University of Toronto, Toronto, Canada; personal communication). For overexpression studies, stable transfections were used with selection for stably transfected pIRES2-EGFP expressing cells achieved by antibiotic selection using Geneticin (Invitrogen) according to standard procedures.

\section{DDR1 expression: Western blotting}

Cell lysates were obtained using Cytobuster (Merck Biosciences, Nottingham, UK) with complete protease inhibitors (Roche Diagnostics). Cells were incubated on ice for $30 \mathrm{~min}$, insoluble cell debris was removed by centrifugation at $10,000 \times g$ for $3 \mathrm{~min}$ and samples combined with an equal volume of loading buffer. Proteins were resolved by electrophoresis using $10 \%$ polyacrylamide-sodium dodecylsulfate gels, blotted on to polyvinylidene fluoride membranes and probed with an anti-DDR1 antibody (Santa Cruz Biotechnology, Heidelberg, Germany) followed by a horseradish peroxidase-conjugated polyclonal goat anti-rabbit secondary antibody (Sigma). Bands were visualised using enhanced chemiluminescence (Amersham Biosciences, Amersham, UK). Equal protein loading was confirmed by reprobing blots for $\alpha$-actin (Sigma).

\section{Quantitative PCR}

RNA was extracted using the QIAGEN RNeasy kit (QIAGEN, Crawley, UK) and contaminating genomic DNA removed using DNAse I (QIAGEN). cDNA was synthesised using Superscript II (Invitrogen). RT-PCR was performed on a Biometra Thermal Cycler using Invitrogen Recombinant Taq DNA polymerase. Procedures were carried out according to manufacturers' instructions. The conditions were $94^{\circ} \mathrm{C}$ for $30 \mathrm{~s}$, $60^{\circ} \mathrm{C}$ for $30 \mathrm{~s}$ and $72^{\circ} \mathrm{C}$ for $30 \mathrm{~s}$ for 35 cycles. PCR products were resolved on a $2 \%$ agarose gel stained with ethidium bromide. For quantitative PCR, the SYBR Green technique was used on a Stratagene Mx3005P real-time PCR system (Agilent Technologies, Stockport, UK), with the following settings for 40 cycles: $95^{\circ} \mathrm{C}$ for $30 \mathrm{~s}, 60^{\circ} \mathrm{C}$ for $30 \mathrm{~s}$ and $72^{\circ} \mathrm{C}$ for $30 \mathrm{~s}$. Each reaction contained $12.5 \mu \mathrm{L}$ Brilliant Green (Agilent Technologies), $6.5 \mu \mathrm{L}$ water, $5 \mu \mathrm{L}$ cDNA and $1 \mu \mathrm{L} 5 \mu \mathrm{M}$ primer mix. Dissociation curves showed a single peak. Primer efficiency was calculated using a dilution curve. Relative expression of transcripts was measured by calculating concentration values relative to a housekeeping gene ( $\beta_{2}$-microglobulin) [27]. Primers were obtained from published literature as follows [28-30]. $\beta_{2}$-microglobulin-forward: GAGTGCTGTCTCCATGTTTGATGT; $\beta_{2}$-microglobulin-reverse: AAGTTGCCAGCCCTCCTAGAG; DDR1-forward: ATGGAGCAACCACAGCTTCTC; DDR1-reverse: CTCAGCCGGTCAAACTCAAACT; DDR2-forward: GGAGG TCATGGCATCGAGTT; DDR2-reverse: GAGTGCCATCCCG ACTGTAATT.

\section{ECM coating of tissue culture plastics}

Rat's tail collagen I (Sigma) diluted to $10 \mu \mathrm{g} \cdot \mathrm{mL}^{-1}$ was applied to tissue culture plastics in a thin layer and allowed to airdry overnight. After extensive washing, collagen-treated and 
control wells were blocked for $1 \mathrm{~h}$ with $1 \%$ bovine serum albumin (BSA; Sigma) in PBS then washed extensively again.

\section{Wound healing assay}

Two epithelial cell types were used. Stable DDR1a-, b- and kdoverexpressing, and control BEAS-2B cells, and BEAS-2B cells exposed to DDR1 or control RNAi were seeded in DMEM/FBS at $1 \mathrm{~mL}$ per well at equal density in 24-well plates (Corning, Artington, UK). After $4 \mathrm{~h}$, cells were serum starved by exchange of medium for BEBM for $24 \mathrm{~h}$. HBECs were seeded at $60 \%$ confluence and then cultured to confluence in a 24 -well plate with $2 \mathrm{~mL}$ per well BEGM exchanged every $48 \mathrm{~h}$. HBECs were transfected when confluent and incubated in BEWM for $48 \mathrm{~h}$ prior to wounding. Two scratch wounds were created in parallel in each well of a 24-well plate [3]. Medium was exchanged for further BEBM or BEWM and photographs were obtained at a fixed point in each wound using an Insight QE Digital camera and software (Image Solutions, Preston, UK) attached to a Nikon Diaphot 300 microscope (Nikon Instruments Inc., Melville, NY, USA) with a $2.5 \times$ NA 0.08 Zeiss lens or $4.0 \times$ NA 0.075 Zeiss lens (Carl Zeiss Ltd., Welwyn Garden City, UK). Further images were obtained at $8 \mathrm{~h}$ for HBECs or $24 \mathrm{~h}$ for BEAS-2B cells. Wound areas were calculated by tracing wounds using Spot software (version 4.6; Image Solutions).

\section{Gelatin zymography}

Supernatants from wounding experiments were combined with an equal volume of $2 \times$ Novex sample buffer (Invitrogen) and separated by electrophoresis through $10 \%$ gelatin gels (Invitrogen) using the Invitrogen Novex system. Gels were exposed to Novex renaturing buffer after electrophoresis and then Novex developing buffer overnight at $37^{\circ} \mathrm{C}$. Recombinant MMP-2 was used as a positive control. Gels were stained using Coomassie blue (VWR International, Lutterworth, UK) dissolved in $40 \%$ methanol, $10 \%$ acetic acid in distilled water, washed and destained using the same solution without Coomassie blue. Images were acquired using SynGene GeneSnap v7.04g attached to a GeneGenius image acquisition system (Synoptics, Cambridge, UK). Calculation of relative sizes of MMP bands was performed using Image 1.39 (National Institutes of Health, Bethesda, MD, USA; http://rsb.info.nih.gov/ij/). The largest band on each gel was selected as the reference size for the region of interest. The same size region of interest was then applied to bands consecutively and the average density determined. The validity of this method was confirmed by determining the density of known concentrations of an MMP-2 standard in a gelatin gel and confirming a linear relationship between density and MMP-2 concentration (data not shown).

\section{MMP-7 ELISA}

MMP-7 was measured by ELISA (minimum detectable concentration of MMP-7 $0.016 \mathrm{ng} \cdot \mathrm{mL}^{-1}$ ) according to the manufacturer's instructions (R\&D Systems, Abingdon, UK). Supernatants from wounding experiments were concentrated five-fold prior to analysis using Vivaspin 500 columns (Scientific Laboratory Supplies, Nottingham, UK).

\section{Cell number}

Equal numbers of cells were seeded into 12-well plates (Corning). For BEAS-2B cells, these were either collagen
I-coated or BSA-coated controls. BEAS-2B cells were exposed to RNAi transfection complex for $48 \mathrm{~h}$ and then seeded at equal density. After $4 \mathrm{~h}$, the medium was exchanged for further BEWM and cells were incubated overnight then fixed with $4 \%$ paraformaldehyde. HBECs were seeded in equal numbers in each well and transfected at $20 \%$ confluence. The medium was exchanged after $4 \mathrm{~h}$. At $48 \mathrm{~h}$, the medium was exchanged again. Cells were fixed after a further $24 \mathrm{~h}$. Nuclear staining was achieved by incubation with $10 \mu \mathrm{g} \cdot \mathrm{mL}^{-1} 4^{\prime}, 6-$ diamidino-2-phenylindole (Sigma) in PBS for $30 \mathrm{~min}$ at room temperature. Fluorescence images were obtained with a $4 \times$ Zeiss lens attached to a Nikon Diaphot 300 microscope using Spot 4.7 software and a Slider RT3 camera (Image Solutions). Nuclei were counted using ImageJ 1.41. The accuracy of this method was confirmed by counting serial dilutions of a cell suspension (data not shown).

\section{Thymidine incorporation}

Equal numbers of cells were seeded into 48-well plates (Corning). For BEAS-2B cells, these were either collagen Icoated or BSA-coated controls. BEAS-2B cells overexpressing DDR1 or empty vector control were seeded in DMEM/FBS and then serum starved for $24 \mathrm{~h}$ once adherent. In HBECs, cells were seeded at equal density, exposed to transfection complexes for $4 \mathrm{~h}$ and then incubated overnight in BEWM. $10 \mathrm{ng} \cdot \mathrm{mL}^{-1}$ EGF was then added and after $8 \mathrm{~h}$ incubation, tritiated thymidine was added at an activity of $1 \mu \mathrm{Ci}(37 \mathrm{kBq})$ per well. After a further $16 \mathrm{~h}$, cells were exposed to $10 \%$ trichloroacetic acid (Sigma) for $30 \mathrm{~min}$ at $4^{\circ} \mathrm{C}$ and DNA was precipitated by incubation with $0.2 \mathrm{M} \mathrm{NaOH}$ (Sigma) overnight at $4{ }^{\circ} \mathrm{C}$. The number of disintegrations was assessed on a Wallac scintillation counter (PerkinElmer, Waltham, MA, USA) after the addition of $10 \mathrm{~mL}$ scintillation fluid per vial.

\section{Adhesion assay}

HBECs were incubated for $48 \mathrm{~h}$ after exposure to RNAi transfection complexes. Adhesion was assessed using the Chemicon cytomatrix adhesion assay kit comprising precoated ECM substrates (vitronectin, fibronectin, laminin, collagen I, collagen IV and albumin control; Fisher Scientific, Loughborough, UK). After treatment, cells were harvested, incubated on various cell matrix factors for $2 \mathrm{~h}$ at $37^{\circ} \mathrm{C}$ in $5 \%$ $\mathrm{CO}_{2}$ and adhesion quantitated according to manufacturer's instructions.

\section{Apoptosis}

HBECs were seeded to eight-well chamber slides at equal density. $24 \mathrm{~h}$ after seeding, cells were exposed to RNAi transfection complexes and incubated for $48 \mathrm{~h}$. HBECs were then fixed using $3.7 \%$ paraformaldehyde, permeabilised with PBS containing $0.1 \%$ Triton $X-100$ and $0.1 \%$ sodium citrate (both Sigma), and then incubated with the Fluorescein In Situ Cell Death Detection Kit (Roche), according to the manufacturer's instructions. Fluorescence images were obtained as described and fluorescent cells were counted using ImageJ 1.41 .

\section{Vital dye exclusion}

Cells were seeded and transfected as for the apoptosis assay. Cells were then incubated with $0.02 \%$ trypan blue in PBS for 
$5 \mathrm{~min}$ at room temperature. Brightfield images were obtained as above and cells were counted using ImageJ 1.41.

\section{DDR1 expression: immunohistochemistry}

Bronchial biopsies were obtained by fibre optic bronchoscopy. Patients with stable asthma were recruited. Control patients without asthma who were undergoing bronchoscopy for other indications, including possible lung cancer and haemoptysis, were also recruited. These patients had normal spirometry and histologically normal airways. The study was approved by the Nottingham Research Ethics Committee (Nottingham, UK) and informed consent was obtained from all patients. Bronchial biopsies were obtained from a first or second subdivision carina. Specimens for staining were fixed in $4 \%$ paraformaldehyde, wax embedded, cut and mounted. Slides were dewaxed in histoclear (RA Lamb Ltd, Eastbourne, UK) and rehydrated through an ethanol series. Sections were either stained with $1 \%$ eosin (Nustain, Nottingham, UK) and haematoxylin (Sigma) or prepared for immunostaining using a Vectastain ABC kit (Vector Laboratories, Peterborough, UK) according to the manufacturers' instructions. Briefly, sections were boiled in $10 \mathrm{mM}$ citrate buffer for $20 \mathrm{~min}$, peroxidase-activity blocked, incubated overnight with anti-DDR1 C20 antibody (Santa Cruz) and the secondary antibody applied according to the manufacturer's instructions. Diaminobenzidine was then applied using the Vectastain DAB kit (Vector Laboratories). Nuclear counterstaining was achieved using haematoxylin. Slides were then dehydrated through a reverse ethanol series and mounted using Vectamount (Vector laboratories).

\section{Statistical analysis}

Observations were compared using unpaired t-tests or oneway ANOVA analysis. Between-group analyses were undertaken using Bonferroni's post-test. Data are presented as mean \pm SEM and $n \geqslant 3$.

a)
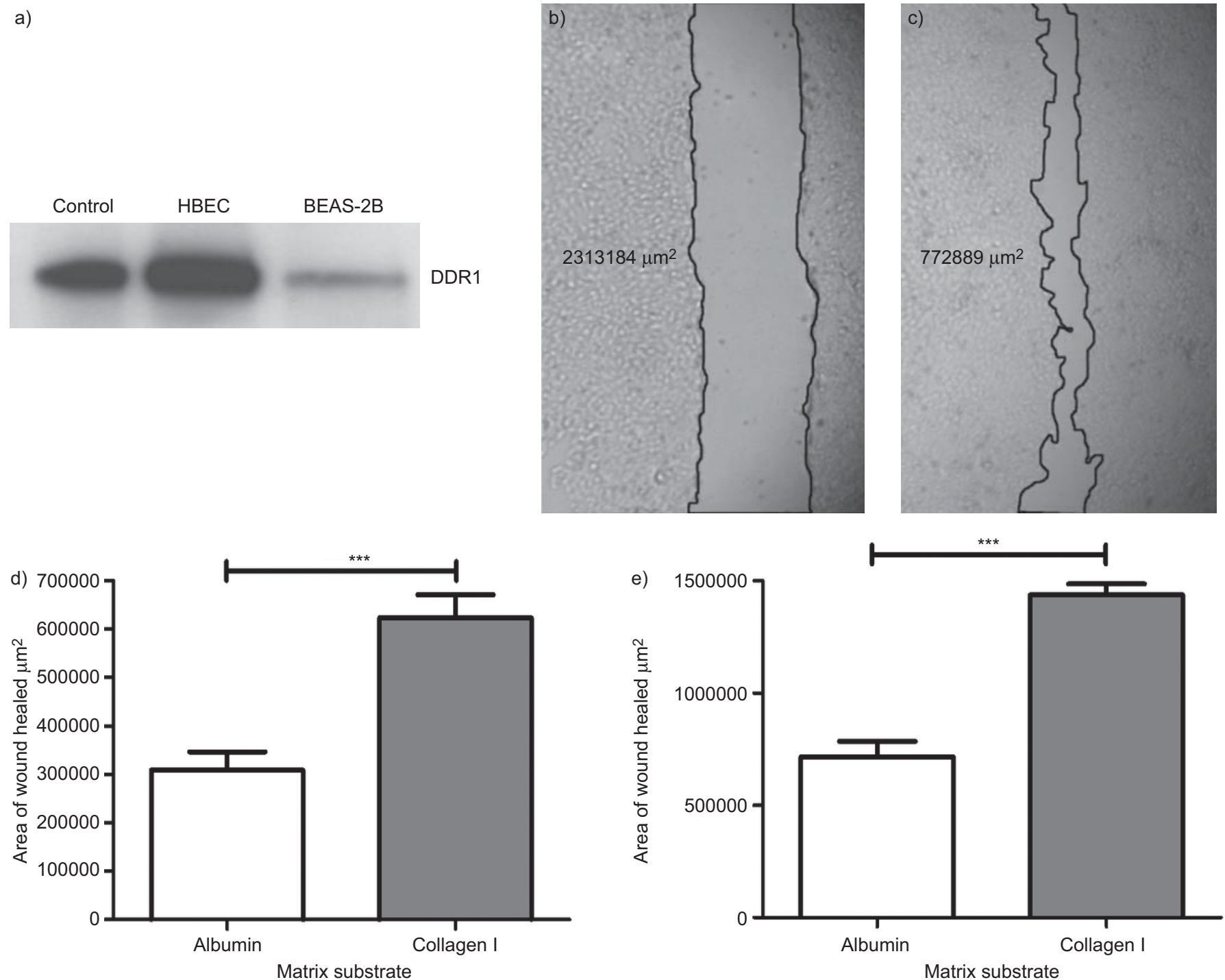

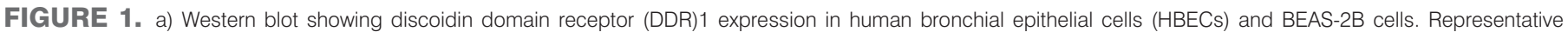

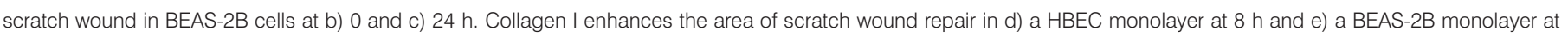
$24 \mathrm{~h}$. Data are presented as mean \pm SEM. $n \geqslant 3$. ${ }^{\star * *}$ : $p<0.001$. 
a)

\begin{tabular}{lll} 
& \multicolumn{2}{c}{ RNAi } \\
\cline { 2 - 3 } HBEC & Control & DDR1
\end{tabular}

DDR1

$\alpha$-actin
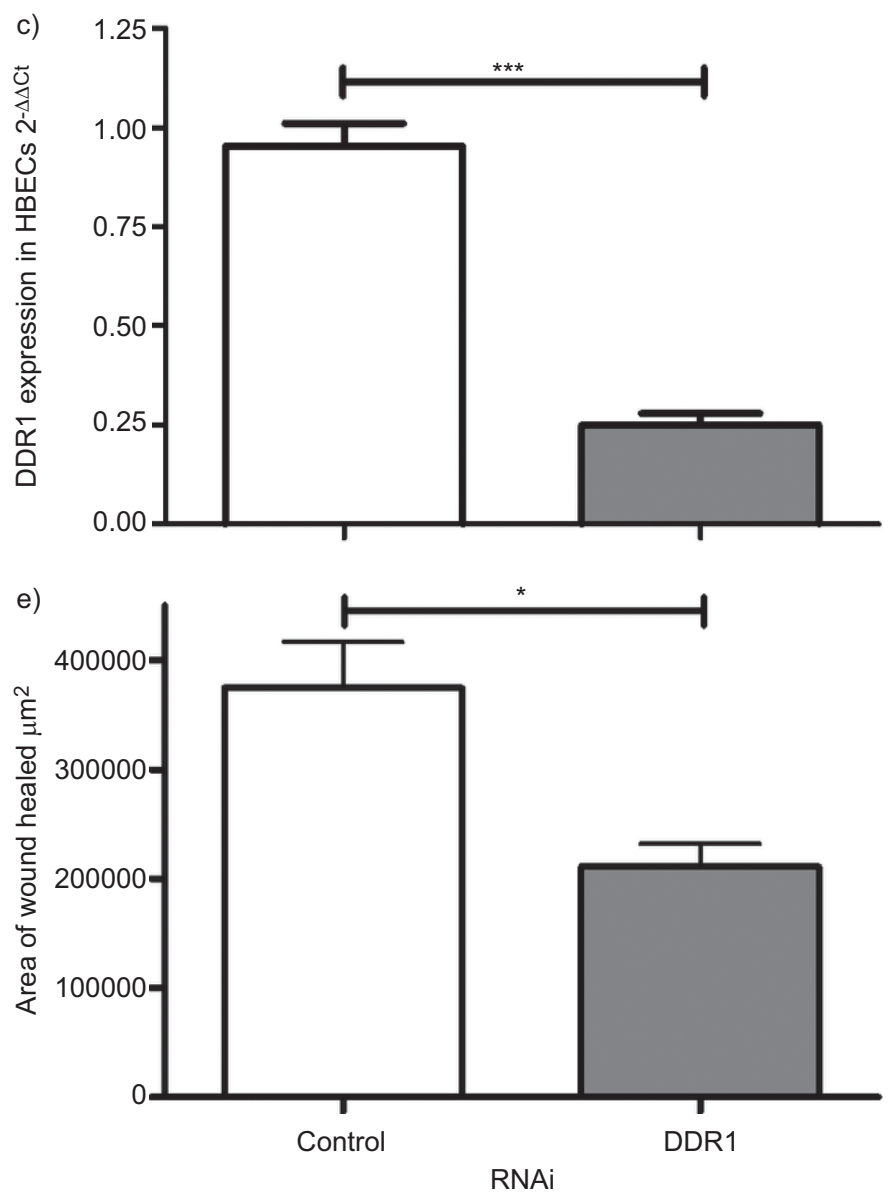

g)

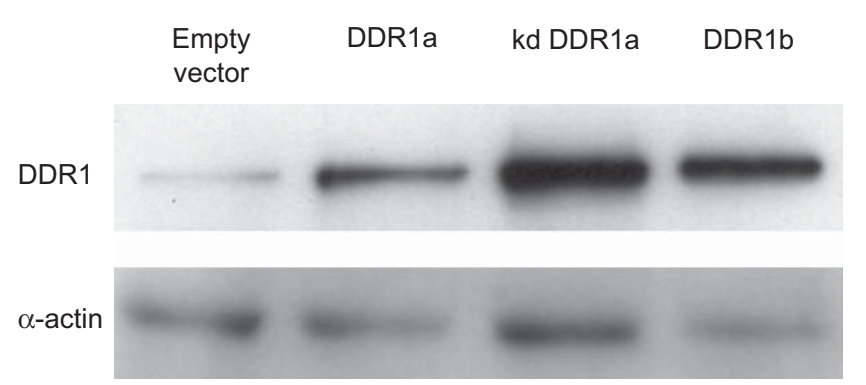

b)
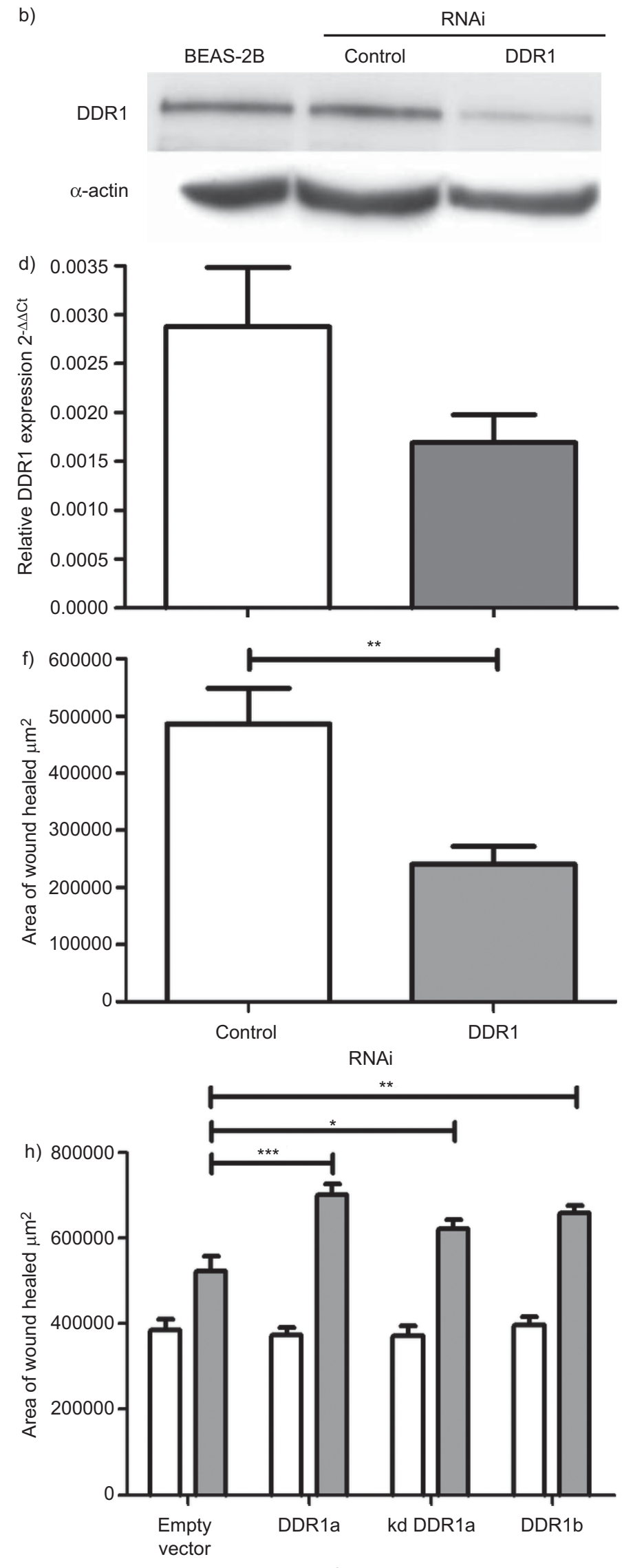

Construct 
FIGURE 2. Discoidin domain receptor (DDR) 1 protein knockdown was confirmed by Western blotting in a) human bronchial epithelial cells (HBECs) and b) BEAS-2B cells $48 \mathrm{~h}$ after transfection. c) Knockdown of DDR1 transcript in HBECs was also confirmed by quantitative RT-PCR $48 \mathrm{~h}$ after transfection. d) There was no significant effect on levels of DDR2 transcript. DDR1 knockdown leads to inhibition of wound repair in both e) a HBEC monolayer and f) a BEAS-2B cell monolayer on a collagen I substrate, compared with control RNA interference (RNAi). g) Overexpression of DDR1 was confirmed by Western blotting. h) Overexpression of all DDR1 isoforms, including kinasedead $(\mathrm{kd})$ DDR1, leads to enhanced wound repair on a collagen I substrate. Data are presented as mean \pm SEM. $n \geqslant 3 .{ }^{*}: p<0.05 ;{ }^{\star *}: p<0.01 ;{ }^{* *}: p<0.001$.

a)

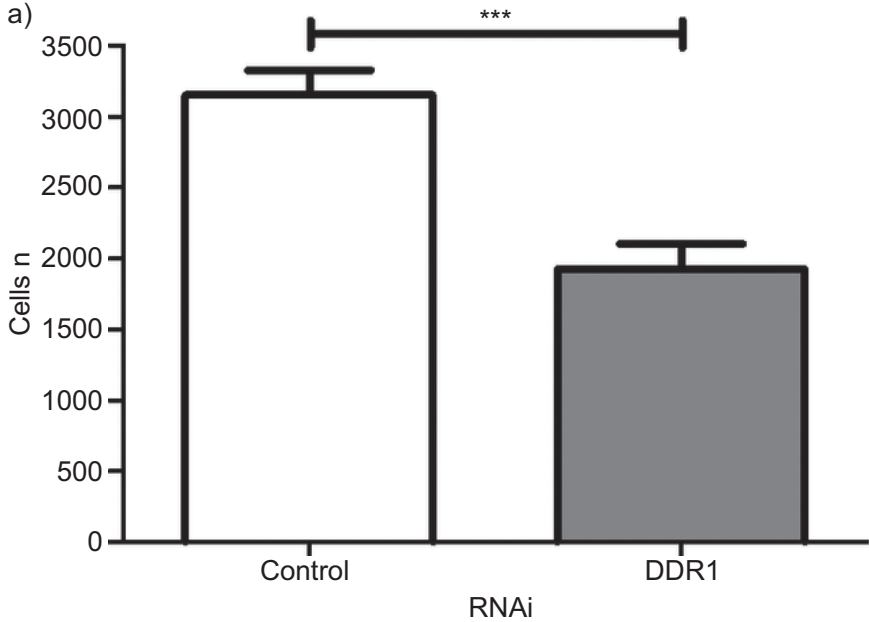

c)
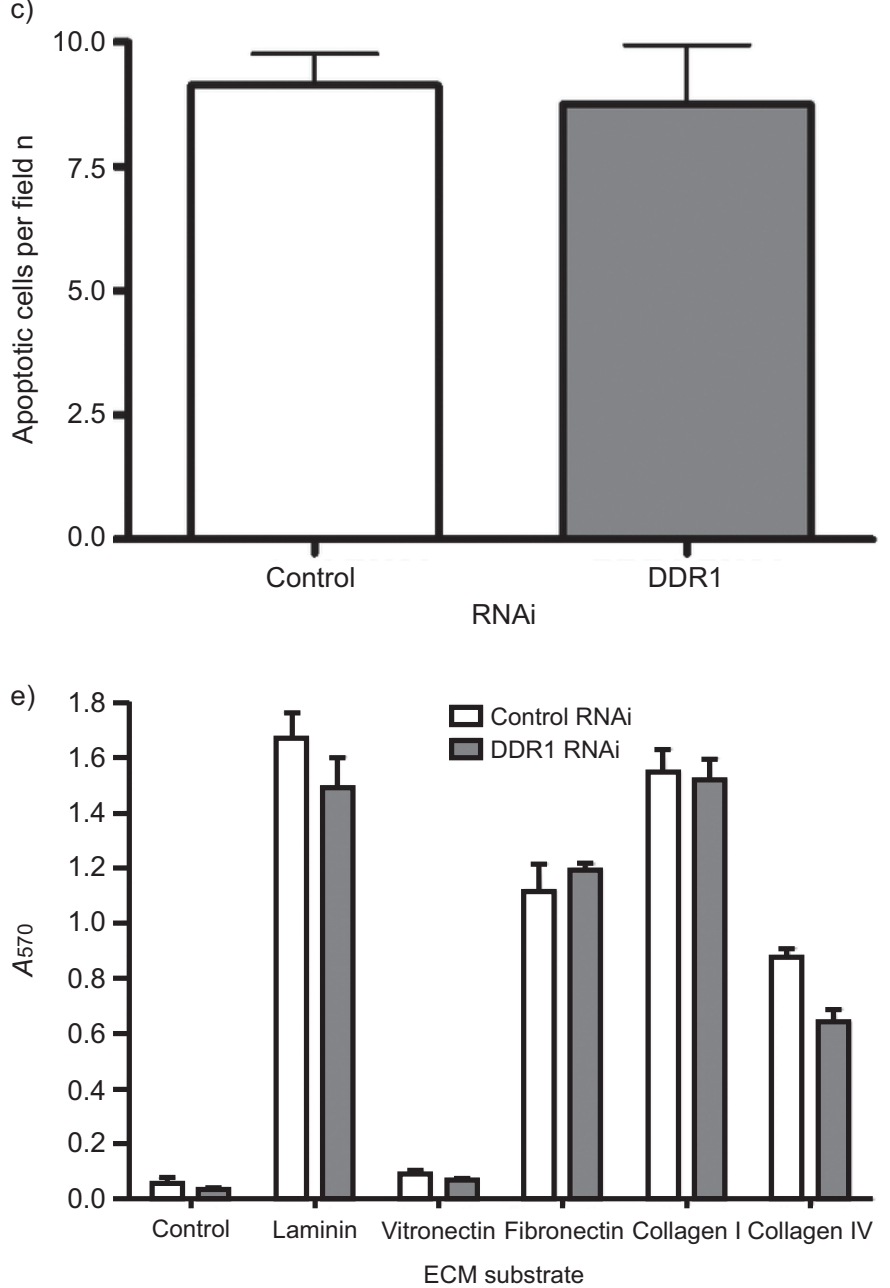
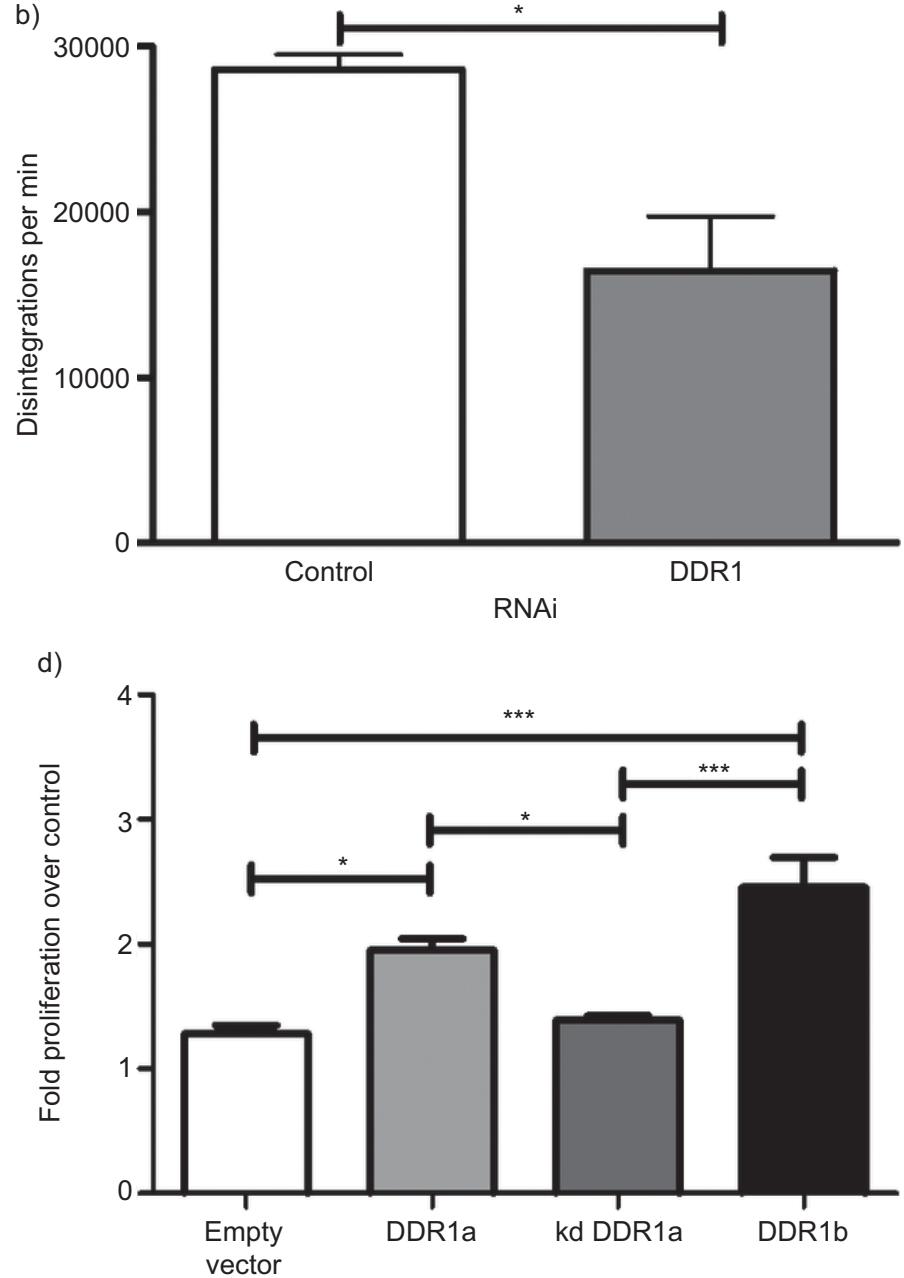

Construct

FIGURE 3. Discoidin domain receptor (DDR)1 knockdown leads to reduced proliferation in human bronchial epithelial cells (HBECs) by both a) cell counting and b) thymidine incorporation, but c) does not promote apoptosis (TUNEL assay). d) By thymidine incorporation, active DDR1 overexpression enhances proliferation in BEAS-2B cells, but overexpression of kinase-dead (kd) DDR1 has no effect. e) DDR1 knockdown has no effect on adhesion of HBECs to extracellular matrix (ECM) proteins. RNAi: RNA interference. Data are presented as mean \pm SEM. $n \geqslant 3$. $*: p<0.05 ; * * *: p<0.001$. 


\section{RESULTS}

\section{DDR1 is expressed in cultured epithelial cells}

To confirm that DDR1 is expressed in both HBECs and BEAS2B cells, we performed Western blotting of cell lysates of both BEAS-2B cells and HBECs (fig. 1a). DDR1 was strongly expressed in HBECs and present at a lower level in BEAS-2B cells. The positive control is a sample validated against a cell lysate known to contain DDR1 obtained from W. Vogel (University of Toronto; personal communication).

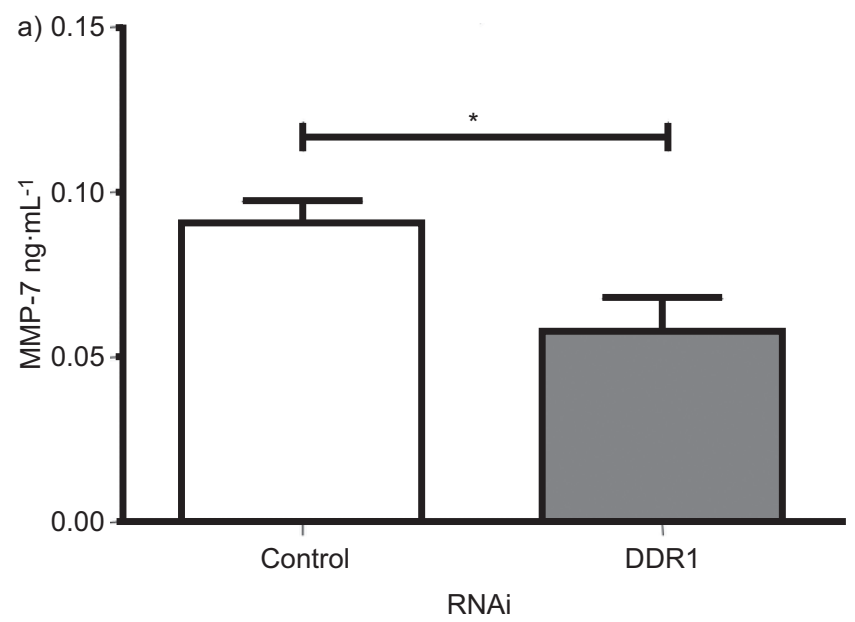

c)
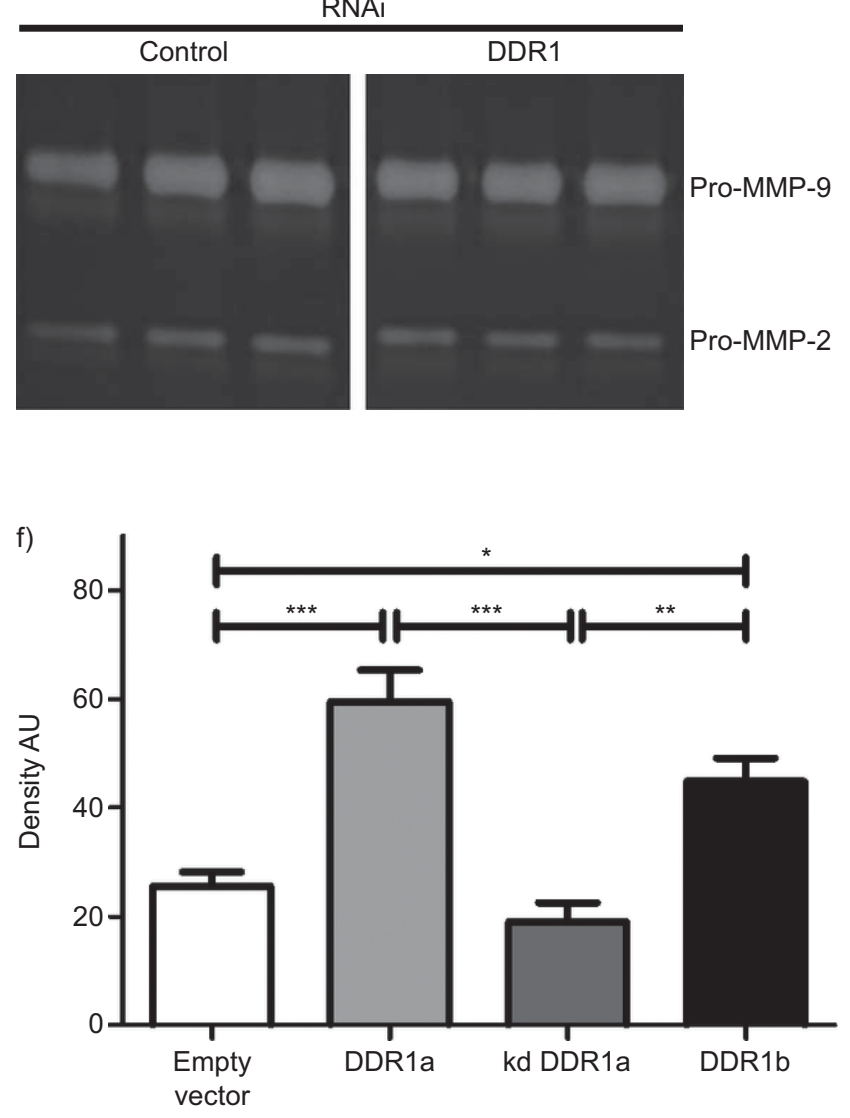

Construct

\section{Collagen I enhances epithelial repair}

In order to investigate the contribution of collagen I (a major component of provisional matrix) to epithelial repair, we compared epithelial repair in the scratch wounding model on collagen I- versus albumin-coated tissue culture plastic [31]. Cells were seeded to near-confluence and then starved of growth factors overnight so that cellular production of other ECM factors could be minimised. In preliminary experiments, we showed that wound healing was significantly faster in HBECs compared with BEAS-2B cells, with $\sim 50 \%$ wound
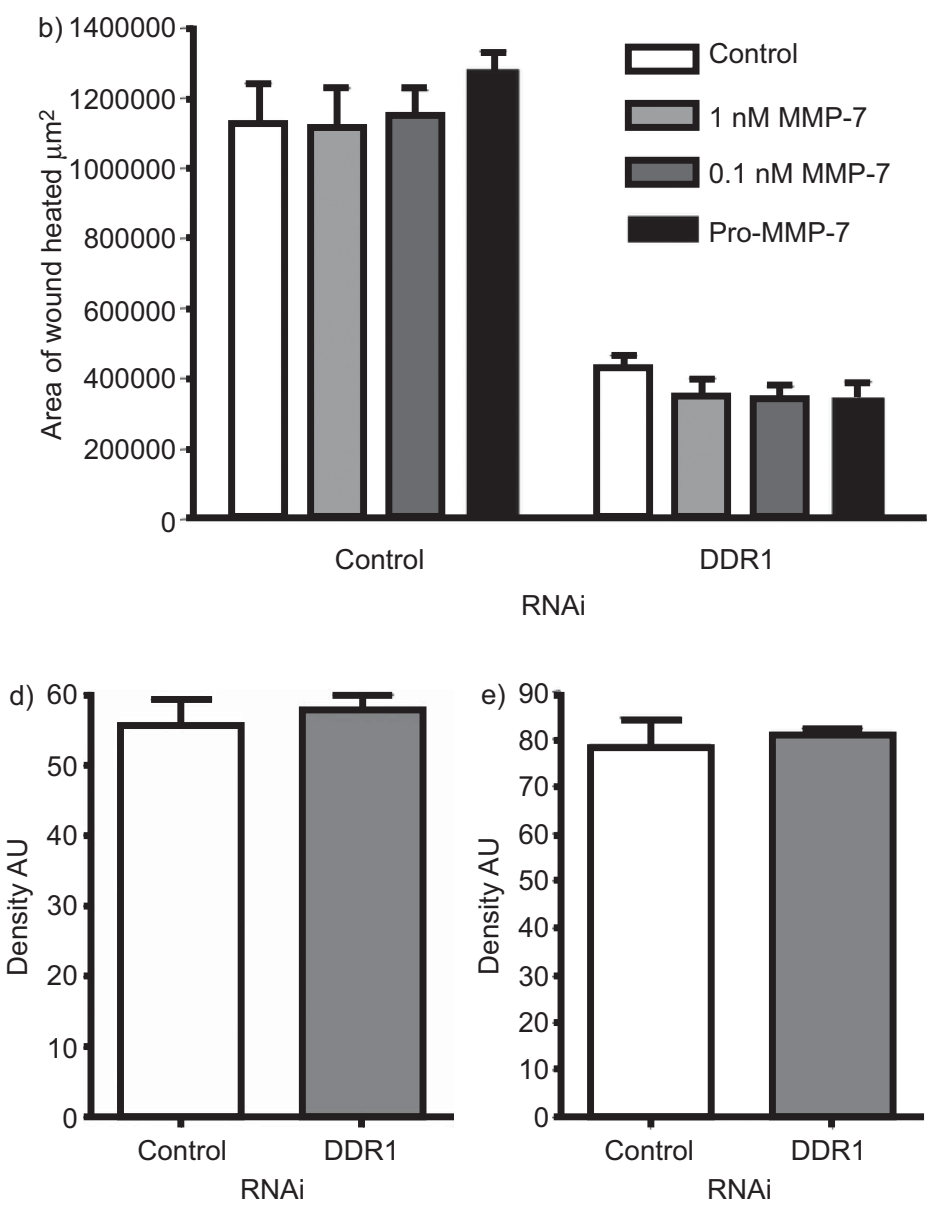

FIGURE 4. a) Discoidin domain receptor (DDR)1 knockdown in human bronchial epithelial cells (HBECs) leads to a reduction in levels of matrix metalloproteinase (MMP)-7. b) Replacement of MMP-7, either amino-phenyl mercuric acetate-activated or pro-MMP-7, does not restore wound repair after DDR1 knockdown. There is no change in levels of c, d) MMP-2 and c, e) MMP-9 after DDR1 knockdown in HBECs. f) In BEAS-2B cells MMP-2 expression is increased by overexpression of DDR1a and DDR1b, but not the kinase-dead $(\mathrm{kd})$ DDR1a. RNAi: RNA interference. Data are presented as mean \pm SEM. $n \geqslant 3$. $*: p<0.05 ; * *: p<0.01 ; * * *: p<0.001$. 
healing after 8 and $24 \mathrm{~h}$, respectively. These time-points were therefore used for further experiments with these cell types (fig. $1 \mathrm{~b}$ and c). Collagen I increased the area of wound healing over that of the albumin control in a BEAS-2B cell monolayer at $24 \mathrm{~h}(2.0$-fold enhancement, 95\% CI 1.58-2.57; p<0.001) and in HBECs at $8 \mathrm{~h}$ (2.0-fold enhancement, 95\% CI 1.41-3.36; $\mathrm{p}<0.001$ ) (fig. 1d and e).

\section{What is the contribution of DDR1 to epithelial repair?}

As collagen $\mathrm{I}$ is the cognate ligand for DDR1, and DDR1 $1^{-/-}$ smooth muscle cells from mice have been shown to exhibit impaired attachment to and migration towards collagen I [32], we hypothesised that the observed effect of collagen on epithelial repair was mediated by DDR1. We first studied the effect of DDR1 knockdown on epithelial repair in both HBECs and BEAS-2B cells using RNAi techniques. In initial experiments we showed by Western blotting that at $48 \mathrm{~h}$ after transfection, DDR1 siRNA resulted in an $89 \%$ reduction in DDR1 protein in HBECs and a 53\% reduction in BEAS-2B cells, when compared with Ambion Control Number 1 (Ambion, Warrington, UK) siRNA (fig. 2a and b). In order to examine the selectivity of the siRNA, we also measured the level of DDR transcripts in epithelial cells (fig. 2c and d). In HBECs, DDR1 transcript was reduced by $74 \%$ by RNAi, whereas DDR2 mRNA was expressed at a low level (300-fold lower than DDR1) and, although it was reduced slightly by DDR1 siRNA, this was not a significant effect. Compared with control siRNA, DDR1 knockdown led to a $46 \%$ reduction in the area of wound healed in BEAS-2B cells at $24 \mathrm{~h}(95 \%$ CI $13-79 \%$; $\mathrm{p}=0.01)$ and a $44 \%$ reduction in the area of wound healed in HBECs at $8 \mathrm{~h}$ $(95 \%$ CI $16-72 \% ; p=0.006)$ (fig. 2 e and $\mathrm{f}$ ).
As epithelial repair is reduced by knockdown of DDR1, we went on to investigate the effect of overexpression of DDR1 on epithelial repair and whether this differs between DDR1 isoforms. Additionally, we assessed the contribution of signalling through DDR1 phosphorylation to epithelial repair. We used BEAS-2B cells overexpressing the two main isoforms of DDR1, DDR1a and DDR1b. A kd version of DDR1a (with a single amino acid substitution, K618A, in the kinase domain) was used to examine whether the repair process was dependent on phosphorylation of DDR1 after activation. Overexpression of all three DDR1 isoforms was confirmed by Western blotting (fig. $2 \mathrm{~g}$ ). In these experiments on an albumin substrate, there was no significant difference in wound healing between empty vector control cells and cells overexpressing DDR1a, kd DDR1a or DDR1b. However, on a collagen I substrate, overexpression of DDR1a, kd DDR1a and DDR1b in BEAS-2B cells were all associated with enhanced wound healing (fig. 2h). For DDR1a, the enhancement over empty vector control was 1.34-fold (95\% CI 1.17-1.52; p <0.001), for kd DDR1a it was 1.19 -fold $(95 \%$ CI $1.01-1.36 ; \mathrm{p}<0.05)$ and for DDR1b it was 1.26-fold (95\% CI 1.09-1.44; $\mathrm{p}<0.01$ ).

\section{DDR1 knockdown was associated with reduced proliferation of HBECs but had no effect on adhesion}

In order to determine which aspect of epithelial repair is affected by DDR1, we went on to investigate the effects of DDR1 knockdown on HBEC proliferation and adhesion. To allow time for DDR1 turnover based on our preliminary findings, as in previous experiments, we measured the increase in cell number induced by $48 \mathrm{~h}$ of exposure to collagen $\mathrm{I}$ in HBECs $48 \mathrm{~h}$ after DDR1 knockdown. We

TABLE 1 Characteristics of asthma patients and nonasthma controls

\begin{tabular}{|c|c|c|c|c|c|c|c|c|c|c|c|}
\hline \multirow[t]{2}{*}{ Sex } & \multirow[t]{2}{*}{$\begin{array}{l}\text { Age } \\
\text { yrs }\end{array}$} & \multicolumn{2}{|c|}{$\begin{array}{l}\text { Lung function } \\
\% \text { pred }\end{array}$} & \multirow[t]{2}{*}{ Smoking history } & \multicolumn{5}{|c|}{ Medication } & \multirow[t]{2}{*}{ Diagnosis } & \multirow[t]{2}{*}{ Sample use } \\
\hline & & FEV1 & FVC & & SABA & ICS & LABA & ocs & $\begin{array}{c}\text { ACh receptor } \\
\text { antagonist }\end{array}$ & & \\
\hline M & 70 & 59 & 70 & Ex-smoker since 1997 & & & & & & Control & $\mathrm{IHC}$ \\
\hline M & 68 & 86 & 71 & 20 pack-yrs & & & & & & Control & $\mathrm{IHC}$ \\
\hline M & 65 & 87 & 101 & Nonsmoker & & & & & & Control & $\mathrm{IHC}$, culture \\
\hline $\mathrm{F}$ & 76 & & & 25 pack-yrs & + & & & & & Control & $\mathrm{IHC}$ \\
\hline M & 76 & 76 & 84 & Nonsmoker & & & & & & Control & IHC, culture \\
\hline $\mathrm{F}$ & 69 & 82 & 96 & 25 pack-yrs & & & & & & Control & Culture \\
\hline M & 29 & 95 & 99 & Nonsmoker & + & + & & & & Asthma & $\mathrm{IHC}$ \\
\hline $\mathrm{F}$ & 19 & 93 & 113 & Nonsmoker & + & + & & & & Asthma & $\mathrm{IHC}$ \\
\hline M & 54 & 72 & 77 & Nonsmoker & + & + & + & & & Asthma & $\mathrm{IHC}$ \\
\hline M & 24 & 107 & 104 & Nonsmoker & + & + & & & & Asthma & $\mathrm{IHC}$ \\
\hline M & 37 & 81 & 111 & Nonsmoker & + & + & & & & Asthma & $\mathrm{IHC}$ \\
\hline M & 26 & 117 & 117 & Nonsmoker & + & & & & & Asthma & $\mathrm{IHC}$ \\
\hline M & 39 & 91 & 93 & Nonsmoker & + & + & + & & & Asthma & $\mathrm{IHC}$ \\
\hline M & 63 & 74 & 121 & Nonsmoker & + & + & + & & + & Asthma & $\mathrm{IHC}$ \\
\hline $\mathrm{F}$ & 41 & 70 & 90 & 4 pack-yrs & & + & + & + & + & Asthma & Culture \\
\hline
\end{tabular}

\% pred: \% predicted; FEV1: forced expiratory volume in 1 s; FVC: forced vital capacity; SABA: short-acting $\beta$-agonist; ICS: inhaled corticosteroid; LABA: Iong-acting $\beta$-agonist; OCS: oral corticosteroid; ACh: acetylcholine; M: male; F: female; IHC: immunohistochemistry; +: medication prescribed. 

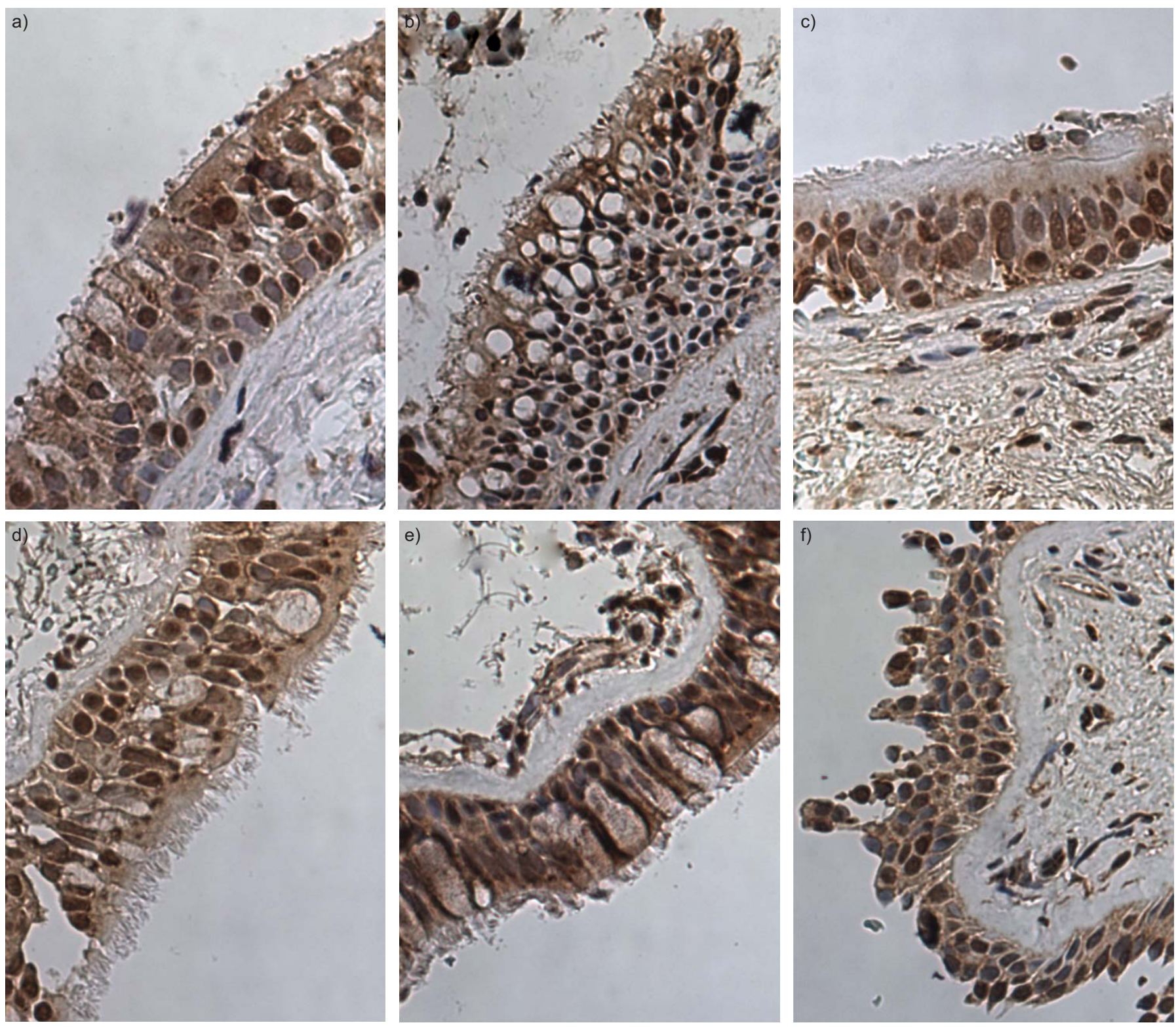

g)

h)

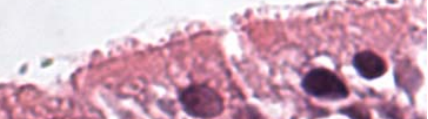

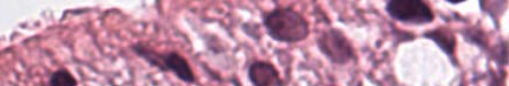

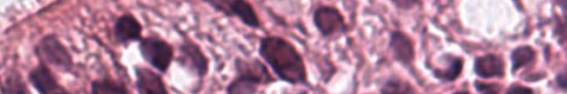
S.S.
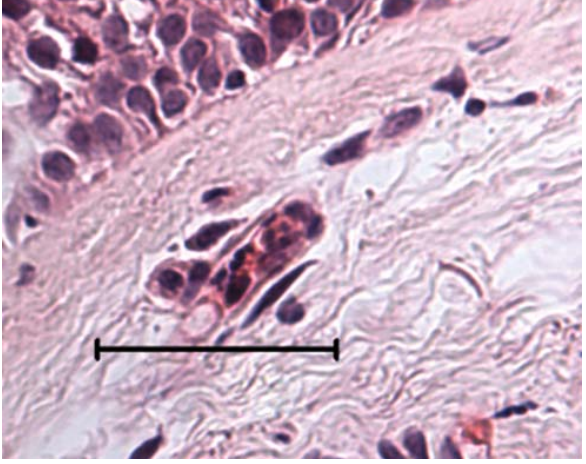

i)
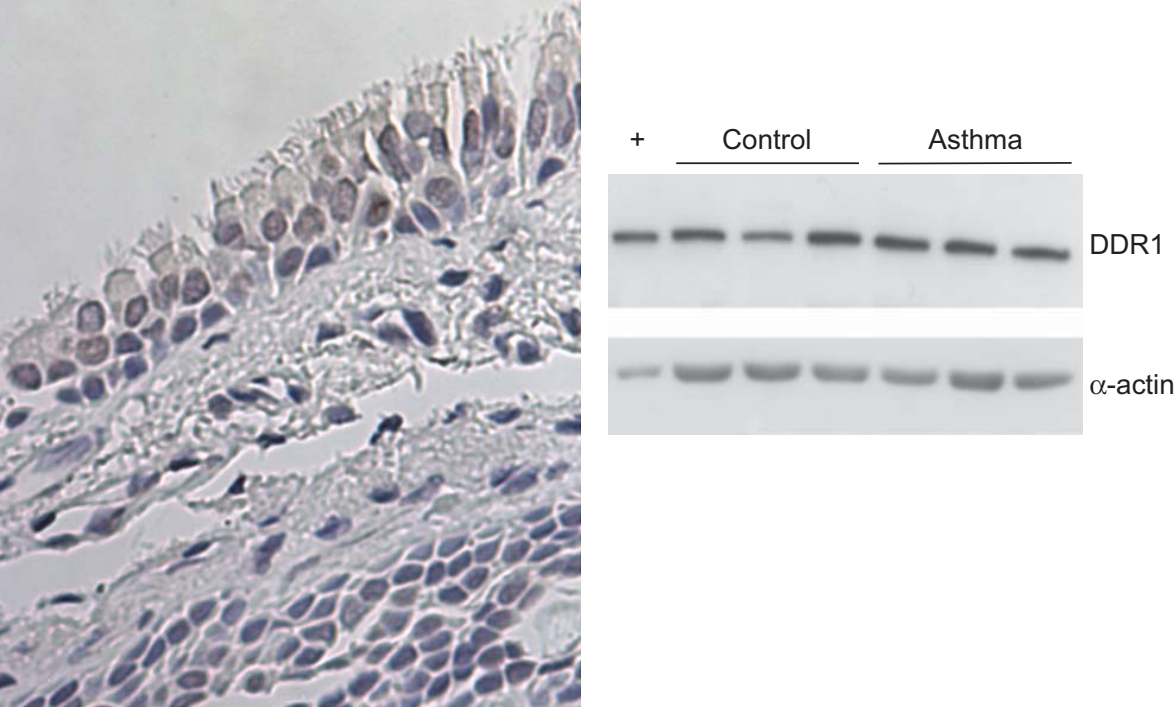

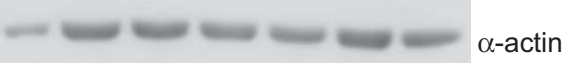




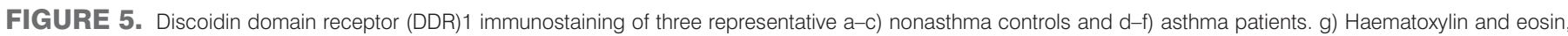

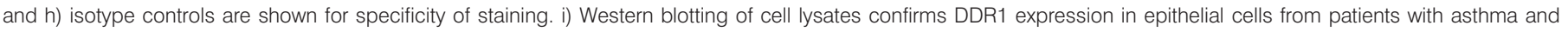
controls. + : positive control. Scale bar $=50 \mu \mathrm{m}$.

incubated cells in BEWM and demonstrated a 30\% reduction in cell number at $48 \mathrm{~h}$ compared with control RNAi by cell counting (fig. 3a) and by thymidine incorporation (fig. 3b). DDR1 has previously been shown to influence levels of p53, a vital regulator of apoptosis [33]. In order to confirm that the effects seen were not due to a reduction in cell viability by DDR1 siRNA, in parallel experiments we confirmed that, although DDR1 siRNA reduced cell proliferation, this was not due to cell death, as the number of cells undergoing apoptosis as confirmed by TUNEL (terminal deoxynucleotidyltransferase uridine triphosphate nick end-labelling) assay did not differ between DDR1 siRNA and control siRNA (fig. 3c). Similar findings were observed in parallel experiments using a trypan blue exclusion assay of cell viability (data not shown). In BEAS-2B cells, proliferation was enhanced in the presence of active DDR1, but not kd DDR1, compared with empty vector control (fig. 3d). DDR1a overexpression enhanced proliferation 1.6-fold (95\% CI 1.1-2.3 fold; $\mathrm{p}<0.05)$ and DDR1b overexpression enhanced proliferation 2.2-fold (95\% CI 1.6-2.7 fold; $\mathrm{p}<0.001)$.

To examine the role of DDR1 on cell adhesion, cells were harvested $48 \mathrm{~h}$ after DDR1 knockdown and seeded in equal numbers onto strips coated with ECM factors. Adhesion was significantly higher on components of the provisional matrix and basement membrane (laminin, fibronectin, and collagens I and IV) than on vitronectin or control (fig. 3e). Adhesion was unaffected by DDR1 siRNA on any ECM substrate.

\section{MMP expression}

MMPs are implicated in the repair of the bronchial epithelium. As MMP-7 is constitutively expressed by HBECs and is a necessary effector of airway epithelial repair [34], we tested the hypothesis that MMP expression is related to DDR1 signalling. We harvested supernatants of DDR1 siRNA and controltransfected HBECs $24 \mathrm{~h}$ after wounding on a collagen I substrate, and measured MMP-7 protein by ELISA, and pro- and active-MMP-2 and MMP-9 by gelatin zymography. In HBECs, DDR1 depletion was associated with a $50 \%$ reduction in MMP-7 protein, similar to the reduction in wound healing (fig. 4a). To determine whether the effects of DDR1 on epithelial repair are mediated solely through MMP-7, we performed wounding experiments in the presence of DDR1 siRNA and added recombinant MMP-7; pro-MMP-7 was added to $1 \mathrm{nM}$, or amino-phenyl mercuric acetate-activated MMP-7 was added to $0.1 \mathrm{nM}$ or $1 \mathrm{nM}$. The addition of MMP-7 did not restore epithelial repair after DDR1 knockdown (fig. 4b). Increasing concentrations of MMP-7 above these levels resulted in epithelial detachment (data not shown). ProMMP-2 and pro-MMP-9 levels were unaffected by DDR1 knockdown in HBECs (fig. 4c-e). Next, we examined the effect of DDR1 overexpression on MMP expression in BEAS-2B cells on a collagen I substrate: although BEAS-2B cells do not produce MMP-7 (data not shown) we observed by zymography that overexpression of DDR1a led to a 2.3-fold increase in MMP-2 protein (95\% CI 1.6-3.0; $\mathrm{p}<0.001)$ and overexpression of DDR1b led to a 1.8-fold increase in MMP-2 protein $(95 \% \mathrm{CI}$
1.1-2.4; $\mathrm{p}<0.05)$. However, overexpression of $k d$ DDR1 had no effect on MMP-2 protein expression (0.74-fold change, 95\% CI 0.054-1.4) (fig. 4f).

\section{DDR1 is expressed in bronchial epithelium}

Having demonstrated that DDR1 is expressed in cultured primary and transformed HBECs, and contributes to epithelial repair, we next tested DDR1 expression in both normal bronchial epithelium and in patients with asthma, a disease characterised by epithelial damage and repair. Samples were obtained from nine asthma patients and six controls by fibre optic bronchoscopy. One of the patients with asthma was treated at step 1, four at step 2, two at step 3, and one each at steps 4 and 5 of the British Thoracic Society Asthma guidelines [35]. All control patients were undergoing bronchoscopy for another indication and had normal spirometry. Patient characteristics are shown in table 1. Specimens from eight asthma patients and five controls underwent immunostaining for DDR1. Histologically, most epithelial specimens were of normal appearance. Specimens from five patients with asthma showed characteristic features of basement membrane thickening or epithelial cell shedding. All epithelia from both controland asthma-derived bronchial biopsies were strongly positive for DDR1 (fig. 5). Staining appeared uniform in nature throughout the epithelium. There was minimal staining of subepithelial structures. Substitution of an immunoglobulin G isotype control for the DDR1 primary antibody abolished this staining. In six patients (three asthma and three control), HBECs were subcultured from biopsies. Protein lysates obtained from these cells underwent Western blotting for DDR1. All patients expressed a single protein band consistent with DDR1.

\section{DISCUSSION}

We have shown that DDR1 is expressed in normal bronchial epithelium and is involved in epithelial repair due to a combination of effects on cell proliferation and migration. DDR1 is required for expression of MMP-7 in HBECs, which is also likely to contribute to epithelial repair.

It is probable that the effects we have observed here are relevant to epithelial repair in vivo, where epithelial wounding exposes ECM containing collagen I, leading to activation of DDR1. Our work and that of others suggests that DDR1 may contribute to these effects by more than one mechanism. In the NIH3T3 mouse fibroblast cell line, activation of DDR1 by collagen I leads to co-localisation of DDR1 with the cytoskeletal protein nonmuscle myosin heavy chain (NMHC)-IIA in 30-60 min, which is faster than the maximal phosphorylation kinetics of DDR1 [19]. NMHC-IIA subsequently binds to the actin cytoskeleton. DDR1-transfected NIH3T3 cells at a wound edge migrate more rapidly than wild-type (DDR1-null) cells [36]. This correlates well with the known pro-migratory effects of DDR1 in mesangial cells, vascular smooth muscle, glioma cells and leukocytes [23, 37-39]. In bronchial epithelium, our study suggests the mechanism of DDR1-enhanced epithelial migration may be due to facilitation of other ECM receptor 
interactions independent of DDR1 autophosphorylation, as all DDR constructs enhanced wound repair, irrespective of phosphorylation. In NIH3T3 cells, collagen I binding to DDR1 dimers leads to dimer aggregation on the cell surface prior to internalisation [40]. Receptor internalisation occurs much more quickly than receptor phosphorylation, suggesting a possible dual mechanism for DDR1 action: interaction with other cell surface receptors independent of phosphorylation at position 618 facilitates migration, while phosphorylation leads to effects on cell synthetic function [26, 40,41].

Consistent with the observation that the kd variant of DDR1 abolishes phosphorylation and subsequent downstream signalling [26], in our overexpression model, although the kd mutant DDR1 enhanced epithelial repair, unlike wild-type DDR1, it had no effect on MMP-2 production or cell proliferation.

MMPs are known effectors of epithelial repair. MMP-7 is constitutively expressed in HBECs, is upregulated in regenerating lung epithelium [7] and MMP-7 knockout in mice abolishes epithelial repair [6]. Our findings show that MMP-7 is reduced in association with DDR1 knockdown in an in vitro wounding model. However, absolute levels of MMP-7 in supernatants were low, which may reflect the relatively small wound area and low number of cells involved in the repair process in this model. MMP-7 replacement at physiological levels did not restore epithelial repair, suggesting that the effect of DDR1 on epithelial repair in this model is likely to work through MMPdependent and -independent pathways. We propose a complementary role of DDR1 and MMP-7 in epithelial repair, where DDR1 promotes migration, which is facilitated by the effect of MMP-7 on cell detachment. This is supported by observations in A549 cells in which either active or pro-MMP-7 was overexpressed. No change in migration of A549 cells was observed, but when active MMP-7 was overexpressed, more cells detached [42]. This is consistent with our observation that MMP-7 replacement does not restore bronchial epithelial repair that has been inhibited by DDR1 knockdown.

DDR1 has been shown to be essential for the maintenance of normal structure and function in skin and kidney [21, 22], and we propose a similar role in lung epithelium. It has been shown that DDR1 co-localises with E-cadherin and that E-cadherin sequesters DDR1 to cell-cell junctions in an intact epithelium [43]. Epithelial cell loss leads to exposure of DDR1 to ECM components with subsequent DDR1 activation, cell migration and, in our model, upregulation of MMP-7. To facilitate cell detachment, MMP-7 may cause loss of cell surface E-cadherin [44], further promoting the effects of DDR1 until the wound is closed, at which point DDR1 activation is reduced, less MMP-7 is produced and E-cadherin can sequester DDR1 to cell-cell junctions. In our study, epithelial repair was enhanced in the presence of DDR1 overexpression, even where the tyrosine kinase was inactive in BEAS-2B cells. This may be explained by the cell-surface molecule expression profile of BEAS-2B cells, which lack E-cadherin, allowing DDR1 to interact with other cell-surface ECM receptors to facilitate migration. Downstream signalling to MMP-7 would not be required to interrupt cell-cell interactions [45].

Our observation that DDR1 knockdown in HBECs did not significantly affect adhesion to various ECM factors may reflect the abundance of other cell adhesion molecules, such as integrins, which together are likely to have a larger effect on cell adhesion than DDR1. Consistent with this idea, it has previously been shown in NIH3T3 cells that adhesion to collagen I after $10 \mathrm{~min}$ is unaffected by DDR1 expression [36].

DDR1 was strongly expressed in the epithelium of the bronchial biopsies from both patients with asthma and nonasthma controls. This suggests that DDR1 expression is not affected by the asthmatic epithelial damage-repair process. However, DDR1 may still play a role in the disease through transduction of signals from the abnormal deposition of subepithelial ECM that is characteristic of the disease. Further studies are required to address this point.

In summary, we have shown that DDR1 regulates bronchial epithelial repair, proliferation and expression of MMPs. These findings warrant further investigation in diseases where epithelium is disrupted, including idiopathic pulmonary fibrosis and acute lung injury, particularly in view of the known upregulation of DDR1 in idiopathic pulmonary fibrosis.

\section{SUPPORT STATEMENT}

The University of Nottingham and Nottingham Respiratory Biomedical Research Unit (Nottingham, UK) supported the investigators during the project.

\section{STATEMENT OF INTEREST}

None declared.

\section{REFERENCES}

1 Holgate ST, Davies DE, Puddicombe S, et al. Mechanisms of airway epithelial damage: epithelial-mesenchymal interactions in the pathogenesis of asthma. Eur Respir J 2003; 22: Suppl. 44, 24s-29s.

2 Sacco O, Silvestri M, Sabatini F, et al. Epithelial cells and fibroblasts: structural repair and remodelling in the airways. Paediatr Respir Rev 2004; 5: Suppl. A, S35-S40.

3 Wadsworth SJ, Nijmeh HS, Hall IP. Glucocorticoids increase repair potential in a novel in vitro human airway epithelial wounding model. J Clin Immunol 2006; 26: 376-387.

4 Boxall C, Holgate ST, Davies DE. The contribution of transforming growth factor- $\beta$ and epidermal growth factor signalling to airway remodelling in chronic asthma. Eur Respir J 2006; 27: 208-229.

5 Oertel M, Graness A, Thim L, et al. Trefoil factor family-peptides promote migration of human bronchial epithelial cells: synergistic effect with epidermal growth factor. Am J Respir Cell Mol Biol 2001; 25: $418-424$.

6 Dunsmore SE, Saarialho-Kere UK, Roby JD, et al. Matrilysin expression and function in airway epithelium. J Clin Invest 1998; 102: 1321-1331.

7 Coraux C, Martinella-Catusse C, Nawrocki-Raby B, et al. Differential expression of matrix metalloproteinases and interleukin- 8 during regeneration of human airway epithelium in vivo. J Pathol 2005; 206: 160-169.

8 Lackie P, Baker J, Gunthert U, et al. Expression of CD44 isoforms is increased in the airway epithelium of asthmatic subjects. Am J Respir Cell Mol Biol 1997; 16: 14-22.

9 Leir SH, Baker JE, Holgate ST, et al. Increased CD44 expression in human bronchial epithelial repair after damage or plating at low cell densities. Am J Physiol Lung Cell Mol Physiol 2000; 278: L1129-L1137.

10 Cambier S, Mu DZ, O'Connell D, et al. A role for the integrin alphavbeta8 in the negative regulation of epithelial cell growth. Cancer Res 2000; 60: 7084-7093. 
11 Herard AL, Pierrot D, Hinnrasky J, et al. Fibronectin and its $\alpha 5 \beta 1$ integrin receptor are involved in the wound-repair process of airway epithelium. Am J Physiol 1996; 271: L726-L733.

12 Holly SP, Larson MK, Parise LV. Multiple roles of integrins in cell motility. Exp Cell Res 2000; 261: 69-74.

13 Montefort S, Baker J, Roche WR, et al. The distribution of adhesive mechanisms in the normal bronchial epithelium. Eur Respir J 1993; 6: 1257-1263.

14 Pilewski JM, Latoche JD, Arcasoy SM, et al. Expression of integrin cell adhesion receptors during human airway epithelial repair in vivo. Am J Physiol 1997; 273: L256-L263.

15 Sheppard D. Epithelial integrins. Bioessays 1996; 18: 655-660.

16 White SR, Dorscheid DR, Rabe KF, et al. Role of very late adhesion integrins in mediating repair of human airway epithelial cell monolayers after mechanical injury. Am J Respir Cell Mol Biol 1999; 20: 787-796.

17 Di Marco E, Cutuli N, Guerra L, et al. Molecular cloning of trkE, a novel trk-related putative tyrosine kinase receptor isolated from normal human keratinocytes and widely expressed by normal human tissues. J Biol Chem 1993; 268: 24290-24295.

18 Shrivastava A, Radziejewski C, Campbell E, et al. An orphan receptor tyrosine kinase family whose members serve as nonintegrin collagen receptors. Mol Cell 1997; 1: 25-34.

19 Vogel W, Gish GD, Alves F, et al. The discoidin domain receptor tyrosine kinases are activated by collagen. Mol Cell 1997; 1: 13-23.

20 Sakamoto O, Suga M, Suda T, et al. Expression of discoidin domain receptor 1 tyrosine kinase on the human bronchial epithelium. Eur Respir J 2001; 17: 969-974.

21 Fukunaga-Kalabis M, Martinez G, Liu ZJ, et al. CCN3 controls 3D spatial localization of melanocytes in the human skin through DDR1. J Cell Biol 2006; 175: 563-569.

22 Gross O, Beirowski B, Harvey SJ, et al. DDR1-deficient mice show localized subepithelial GBM thickening with focal loss of slit diaphragms and proteinuria. Kidney Int 2004; 66: 102-111.

23 Hou G, Vogel W, Bendeck MP. The discoidin domain receptor tyrosine kinase DDR1 in arterial wound repair. J Clin Invest 2001; 107: 727-735.

24 Selman M, Pardo A. Role of epithelial cells in idiopathic pulmonary fibrosis: from innocent targets to serial killers. Proc Am Thorac Soc 2006; 3: 364-372.

25 Zuo F, Kaminski N, Eugui E, et al. Gene expression analysis reveals matrilysin as a key regulator of pulmonary fibrosis in mice and humans. Proc Natl Acad Sci USA 2002; 99: 6292-6297.

26 Vogel W, Brakebusch C, Fassler R, et al. Discoidin domain receptor 1 is activated independently of $\beta_{1}$ integrin. J Biol Chem 2000; 275: 5779-5784.

27 Nolan T, Hands RE, Bustin SA. Quantification of mRNA using real-time RT-PCR. Nat Protoc 2006; 1: 1559-1582.

28 Ford CE, Lau SK, Zhu CQ, et al. Expression and mutation analysis of the discoidin domain receptors 1 and 2 in non-small cell lung carcinoma. Br I Cancer 2007; 96: 808-814.

29 Keller MS, Ezaki T, Guo RJ, et al. Cdx1 or Cdx2 expression activates E-cadherin-mediated cell-cell adhesion and compaction in human COLO 205 cells. Am J Physiol Gastrointest Liver Physiol 2004; 287: G104-G114.

30 Yoshinaga $\mathrm{K}$, Inoue $\mathrm{H}$, Utsunomiya $\mathrm{T}$, et al. $\mathrm{N}$-cadherin is regulated by activin $\mathrm{A}$ and associated with tumor aggressiveness in esophageal carcinoma. Clin Cancer Res 2004; 10: 5702-5707.

31 Wadsworth SJ, Henderson N, Johnson SR, et al. Wounded mucociliated human bronchial epithelial cultures release factors which trigger migration of human airway smooth muscle cells. Am J Respir Crit Care Med 2007; 175: Suppl., A121.

32 Hou G, Vogel WF, Bendeck MP. Tyrosine kinase activity of discoidin domain receptor 1 is necessary for smooth muscle cell migration and matrix metalloproteinase expression. Circ Res 2002; 90: 1147-1149.

33 Ongusaha PP, Kim JI, Fang L, et al. p53 induction and activation of DDR1 kinase counteract p53-mediated apoptosis and influence p53 regulation through a positive feedback loop. EMBO J 2003; 22 : 1289-1301.

34 Parks WC. Matrix metalloproteinases in lung repair. Eur Respir J 2003; 22: Suppl. 44, 36s-38s.

35 British Thoracic Society. British Guideline on the Management of Asthma. Thorax 2008; 63: Suppl. 4, iv1-iv121.

36 Huang Y, Arora P, McCulloch CA, et al. The collagen receptor DDR1 regulates cell spreading and motility by associating with myosin IIA. J Cell Sci 2009; 122: 1637-1646.

37 Curat CA, Vogel WF. Discoidin domain receptor 1 controls growth and adhesion of mesangial cells. J Am Soc Nephrol 2002; 13: 26482656.

38 Kamohara H, Yamashiro S, Galligan C, et al. Discoidin domain receptor 1 isoform- $\alpha(\mathrm{DDR} 1 \alpha)$ promotes migration of leukocytes in three-dimensional collagen lattices. FASEB J 2001; 15: 2724-2726.

39 Ram R, Lorente G, Nikolich K, et al. Discoidin domain receptor-1a (DDR1a) promotes glioma cell invasion and adhesion in association with matrix metalloproteinase-2. J Neurooncol 2006; 76: 239-248.

40 Mihai C, Chotani M, Elton TS, et al. Mapping of DDR1 distribution and oligomerization on the cell surface by FRET microscopy. J Mol Biol 2009; 385: 432-445.

41 Noordeen NA, Carafoli F, Hohenester E, et al. A transmembrane leucine zipper is required for activation of the dimeric receptor tyrosine kinase DDR1. J Biol Chem 2006; 281: 22744-22751.

42 McGuire JK, Li Q, Parks WC. Matrilysin (matrix metalloproteinase-7) mediates E-cadherin ectodomain shedding in injured lung epithelium. Am J Pathol 2003; 162: 1831-1843.

43 Wang CZ, Yeh YC, Tang MJ. DDR1/E-cadherin complex regulates the activation of DDR1 and cell spreading. Am J Physiol Cell Physiol 2009; 297: C419-C429.

44 Noe V, Fingleton B, Jacobs K, et al. Release of an invasion promoter E-cadherin fragment by matrilysin and stromelysin-1. J Cell Sci 2001; 114: 111-118.

45 Atsuta J, Sterbinsky SA, Plitt J, et al. Phenotyping and cytokine regulation of the BEAS-2B human bronchial epithelial cell: demonstration of inducible expression of the adhesion molecules VCAM-1 and ICAM-1. Am J Respir Cell Mol Biol 1997; 17: 571-582. 